\title{
Developing Elements of User Experience for Cellular Phones and Services: Evidence from Pakistan
}

\author{
Syed Asim Ali \\ Department of Computer Science, \\ University of Karachi, Pakistan
}

\author{
Urooj Waheed \\ Faculty of Computer Science, IBA, \\ Karachi, Pakistan
}

\author{
Hira Anwar Khan \\ Faculty of Computer Science, IBA, \\ Karachi, Pakistan
}

\begin{abstract}
User Experience is a multidimensional concept, up until now it has not be given a definition that is acceptable by all the community. This study focuses on the attributes that define user experience. There are three distinct instruments used to find the relevant details. The instruments are review, survey and indirect observation. All the instruments were collected from different sections. To find the elements as well as the underlying elements that are important. The most influential elements were Usability, User Subjective Value, Affect and Performance. It suggests a model that not only discuss the sub elements but it also outlines the factor that instigate user experience. Future work includes analysis of variables using PCA and Regression analysis.
\end{abstract}

\section{Keywords}

Usability, User Affect, User Experience, User Subjective Value

\section{INTRODUCTION}

User Experience is considered a concept with many dimensions; an accepted definition of the domain is still missing. Many prior researchers have found different measures that influence usability [8]. One of the researchers found Usability, User Affect and User Subjective value to be the elements that define User Experience [1]. Other found that User Experience is influenced by customer satisfaction and loyalty [4]. A third very comprehensive study on co-experience found that the experience gained when interacting also have a profound impact on User Experience. Co-experience largely impacts product or service experience [6]. In a study on positive user experience; it was found that by fulfilling generic hygiene needs of users create a positive user experience [5]. These researches highlight the need for developing elements of User Experience and also to find ways to find evidence according to cultural settings [11].

Many researches have been done to find the universal definition of User Experience [4, 5]. HCI experts don't agree on one of the definitions coined by these researched [1]. This study analyses some aspects of User Experience and how they are recognized by the users, Practioners and Academia. Three different research instruments were used according to the type of participant involved. The articles published in the best of journals with high impact factor were considered to find the underlying aspects of user experience. A detailed review of the literature was done. Then using the elements found in the literature were used to question Practioners working in the HCI, UI, UX and Human factor fields. The aspect of user experience that were found by academia were verified by the Practioners. Furthermore, to find the detail of the elements that influence user experience a survey using DRM method [1] was done to gain evidence from Users themselves.

User experience was explored for Cellular Phones and its Services. This survey was done in Pakistan and only illustrates the evidence from Pakistan. The reason for this choice was easy access and relatively constructed concepts. Users of mobile phones are in millions in Pakistan. Although the penetration rates are low but in rural areas. As the research was conducted in urban Sindh therefore evidence was easier to find.

\section{REVIEW OF THE RELATED LITERATURE}

This section started off by screening different articles. All the articles were screened on the basis of their relevance to the subject and the quotient of user experience discussed in it. Below is the crux of the literature reviewed. The following were found to be the most important factor in creating user experience.

The most comprehensive study was found to be Park et. al. It used a range of instruments to measure the factors. Also the evidence was quite accurate as it was tested with academia, industry and end-users. The factors found to have the most impact on user experience were Affect, User Subjective Value and Usability. Also Park et. al. described the sub elements of user experience by using the End Users perspective [1].

Some other studies focused on the context rather than the influence. The study discussed the categorization and the context of User Experience in the context of cellular products. The results showed a view of how context affects UX. This becomes practical in identifying the most meaningful user experiences among the reported ones. We propose that triggering context analysis should become a part of user experience studies of mobile products [2][8].

Some others investigated how specific memories of their experiences with their use of mobile phones to guide their behavior and their willingness. [4] The results proved that the quality of the user experience UX curve method and the longterm effects that improve the user experience of users and researchers can determine or cause it to deteriorate [11]. Methods to provide rich qualitative data and perceived attractiveness of mobile phones that we have seen an improvement trend was related to user satisfaction and willingness to recommend friends on their phone [7]. This highlights the perceived attractiveness of the existence of mobile phones, such as personal interactive user acceptance of the product may be a differentiating factor.

professionals and academics Human-Computer Interaction look for ways to expand their understanding of what constitutes "pleasant experiences with technology." [5].

The experience is a constructive activity. Co-experience is the user experience, resulting in social interaction. Coexperience is the seamless blend of usability of products and social interaction. The experience, while substantially by the other users would not be the same, or even possible, without the presence of the product and the possibilities for an experience that it provides [6].

One of the study attempts to clarify experience in interactive systems. It characterizes current approaches from a number of disciplines to experience and a framework for presenting experience for interactive system design. It demonstrates how 
the framework can be applied by the members of a multidisciplinary team, to understand, and could provide the

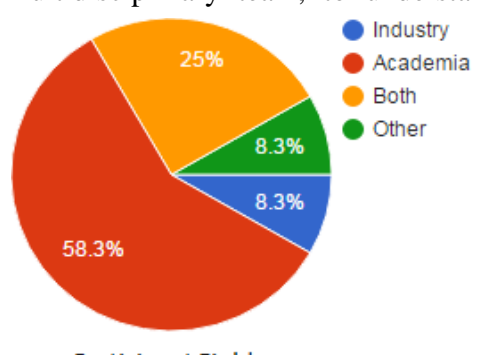

Participant Field

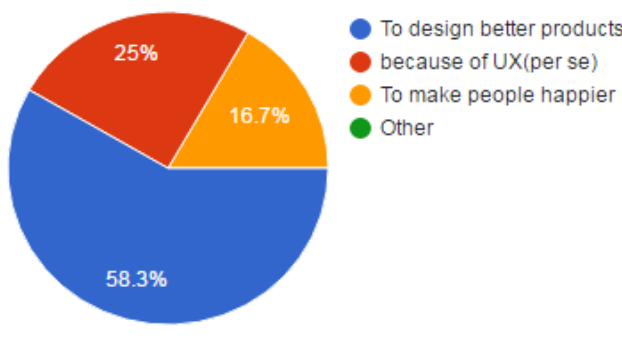

Factor for Interest in UX

\section{METHODOLOGY}

\section{Survey}

A survey was conducted where participants were Practioners and end users. Total of 12 respondents were selected for the survey to find the elements of user experience while using cellular phone and its application. Academia and researchers are focus for UX theories and frameworks, on the other hand mobile users emphasize more on attributes, such as functionality. Each kinds of interactions and experiences new product and system designs generate.
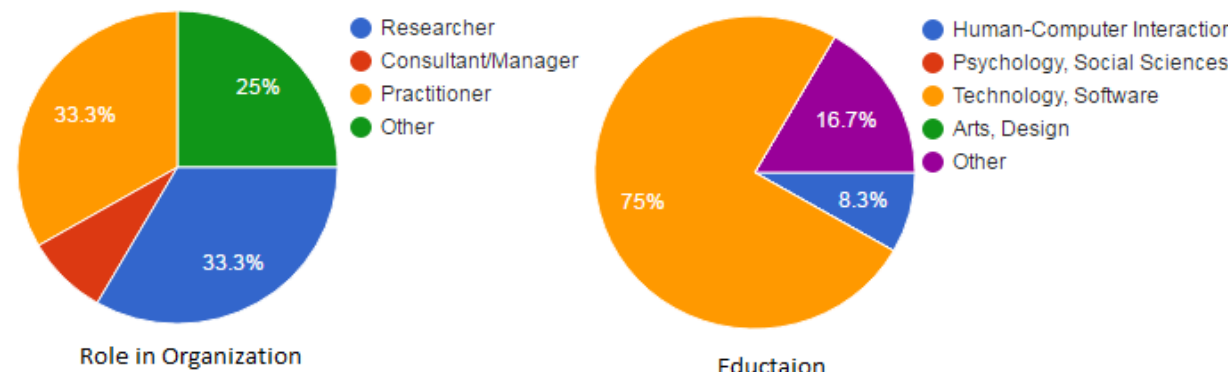

Eductaion

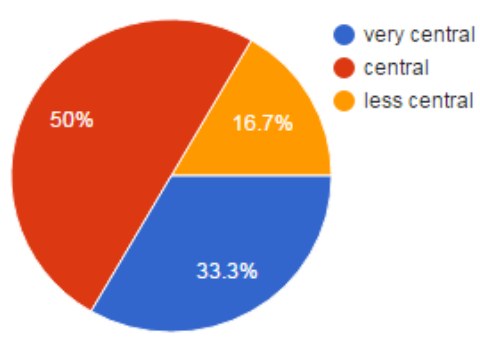

Professional Role as per UX

respondent is asked to mark the degree of agreement and disagreement on likert scale of 1-5 ((1: strongly disagree, 2: disagree, 3: neither agree nor disagree, 4: agree, 5: Strongly agree). Respondents were provided with the open ended question in which they were asked to provide the three most important factors influencing UX which they think to be best suited while using mobile phone and its services.

The survey questionnaire was divided in three parts.

\begin{tabular}{|c|c|c|}
\hline Questions & Mean & SD \\
\hline 1. Service experience as well as product experience belongs to UX & 4.166667 & 0.834847 \\
\hline 2. The user can gain UX without interacting with a product & 2 & 1.128152 \\
\hline 3. A nonprofit product brings UX & 3 & 1.206045 \\
\hline 4. UX occurs because of the users relationship with a corporation & 2.833333 & 1.267304 \\
\hline 5. UX exists before the actual use of a product & 3.666667 & 1.669694 \\
\hline 6. Promotional activities before a product launch bring UX & 3.416667 & 1.083625 \\
\hline 7. Usability of a product and users affect influence UX & 4.5 & 0.522233 \\
\hline 8. The users subjective value toward a product influences UX & 4.166667 & 0.834847 \\
\hline 9. Information given by other users influences UX & 4.583333 & 0.668558 \\
\hline 10. Previous experience with similar products influences UX & 4.333333 & 1.230915 \\
\hline 11. Culture background of the user influences UX & 3.666667 & 1.073087 \\
\hline
\end{tabular}

First part consists of questions about background and demographics of the respondents.

Second part consists of close ended questions about definition and scope of User Experience.

Third part consists of close ended questions about elements of User Experience.

\section{A. Demographics}

Out of 12 respondents 7 works in academia, 1 work in industry, 3 works in academia and in industry both, 1 works in other. 4 out of 12 respondents play role of researchers, 4 play role of Practitioner, 1 as manager/Consultants, 3 others. 9 out of 12 respondents belong to the field of Technology, Software, one belongs to Human-Computer Interaction, and two belong to others. 7 respondents want to understand about the nature of UX because they want to develop and design better, interactive products, 3 respondents just want to learn about UX, 2 
respondents want to make people happy by making simple products.

Six respondents are of opinion that the UX is essential part of their professional work, four respondents think UX is more than essential part, two respondents don't consider UX as essential to professional work.

\section{B. User Experience and Scope}

More than $90 \%$ of respondents agree to the fact that Service experience as well as product experience belongs to UX. 75\% respondents disagree that the user can gain UX without interacting with a product, $8.3 \%$ responds neutrally, $16.7 \%$ agree that the user can gain UX without interacting with a product. $33.3 \%$ respondents agree that a nonprofit product brings UX, $41.7 \%$ respondents are neutral, and $25 \%$ disagree with the statement.

Almost fifty percent of respondents neither agree nor disagree about the statement that UX occurs because of the user's relationship with a corporation, $25 \%$ disagrees and $25 \%$ agrees with the statement. $25 \%$ respondents disagree about the fact that UX exists before the actual use of a product and $75 \%$ agrees. $25 \%$ of the respondents are of the opinion that promotional activities before a product launch bring UX, $16.6 \%$ disagree and $58.3 \%$ agrees.

\section{C. User Experience Elements}

All respondents agree to the fact that Usability of a product and user's affect influence User Experience (UX). 75\% respondents agree that the user's subjective value toward a product influences UX and $25 \%$ are Neutral to the statement. 91.7\% respondent agree to the statement that information given by other users influences UX and 8.3\% neither agree nor disagree. 83.4\% respondent agree that previous experience with similar products influences UX, 8.3\% disagree and $8.3 \%$ neither agree nor disagree. $58.3 \%$ state that Culture background of the user influences UX, 25\% neither agree nor disagree, and $16.7 \%$ disagree.

Respondents also asked about the important factors affecting UX (open-ended question). 8 respondents out of 12 states Usability as important factor, 7 respondents out of 12 states Affect is important factor, 7 respondents out of 12 states User Value is important factor, and 1 select Performance is important factor.

\section{INDIRECT OBSERVATION}

Indirect observation was used as an instrument for recording data from end users; in this case the cellular phone users.

\section{A. $\quad$ Survey with mobile users}

This survey is conducting for getting the information about the experience of the users while they are interacting with their mobile phones on daily basis. The experience sampling method (ESM) is used for the survey. In this method respondents are asked to record their experiences randomly while performing different activities like, call, sms, video call, email, etc. through this log user experience with product will be studied. Recording every single activity is time consuming as well as costly, so instead day reconstruction method (DRM) is used. In this approach users will record their experience thrice a day.

\section{B. Survey Design}

Survey using DRM was conducted to record users experience with mobile and its application. Mobile phone is used frequently so it is impossible and tedious task to record all the activities instead all respondents were asked to record their response thrice a day while using different activities. They were asked to write about the series of episodes. Each episode consisted of time of activity, title of episode, place, affair, feeling related to affair, name, gender, occupation, brand of mobile.

\section{C. Survey Design}

The second Phase of Survey is to record the experience of the mobile users. For this purpose, different type of users was selected so as to get the result more accurate because factors which influence the factors of UX are social, cultural, age, occupation, brand of phone etc. The time duration for which user possess a particular brand, plays an important role because as the time increases respondent become partial towards the brand. Total of 12 participants were chosen for the survey, among them $55 \%$ are males and $45 \%$ are females. 1 was house wife, 2 were school students, 1 was office worker, 2 were teachers, and 6 were students. 6 out of 12 had android phones, 2 had iphone, 4 had ordinary phones. As we cater different age groups so for all of them it is not possible to remember each activity for the survey.

\section{C.1 Example of Episodes}

\section{i. $\quad$ The title of episode: Silly Chat}

\section{Beginning and end of time: 1:20am to 1:31am}

Place: home

Affair: Silly chat with a stupid friend who just came back from hospital

Feelings related to this affair: So, this really good friend of mine was not feeling down after visiting the doctor as the doctor told him that they might operate him. During the conversation, I was trying to cheer him up and this was when I explored the Faceboomk messenger emoticons and nicknames features. There more features that included chat window color picker etc. Not only technology has connected us to people living far away but also it has enabled us to send our emotions to the other side and BE SILLY in our own ways.

\section{ii. The title of episode: Sending Email Beginning and end of time: 12:20:00 to 2:00:00 PM}

Place: At campus

Affair: Had to send important assignment emails to friend

Feelings related to this affair (including reasons for the feeling): I realized iPhone $4 \mathrm{~s}$ has no option for attachments in email. Had to delay till I could use my pc to send the email.

UX is ambiguous, it is a vast term and its definition is still not proposed by the experts. it can be decomposing into concrete attributes. It was found in the survey that UX can be influence by three elements Usability, Affect, and User Subjective Value. DRM survey is helpful in analyzing the subelements of the user experience further. The identifying process consisted of three steps: (a) developing an initial list, (b) mapping episodes on the list, and (c) revising the list [1].

The initial list which was formed by study can be further enhance on the result collected from the survey of episodes. Total of 42 episodes were collected from 12 respondents.

\section{CONCEPTUALIZING UX}

UX cannot be defined but it could be explained in terms of factors through which it can be calculated. The measures that can explain the user experience are usability, user subjective value, affect and Performance. Considering this there are also components which can help instigate User experience by emoting 
in a way that user is made to take an action (e.g. buy product) getting the desired result explaining User Experience. The following Expression describes the condition.

\section{User experience $=$ actions + result + emotion}

Taking all these measures into account. Not only the measures found in the study are important but also the user activity measures are also important. In the following section all these measures are defined and explained.

\section{A Usability}

A product is usable when user is able to perform an intended task completely. Usability is the measure which tell how well the information architecture, design, content and other elements work together to enable users to accomplish their goals.

Usability is the most important feature when considering UX. Simplicity, flexibility and learnability were found to be the subelements of Usability.

\section{B User Subjective Value}

User Value relates to the level of confidence, trust and comfort that users feel when using a mobile or app. According to a 2011 study by Truste and Harris Interactive, privacy and security are the top two concerns among smartphone users

User subjective value turns to be the most dispersed and dependent on the user itself. Its underlying elements were found to be self-satisfaction, pleasure and Socialability

\section{C Affect}

This has to do with the visual presentation and interactive experience of mobile, including graphic design, branding and layout.

Affect is found to be the most describing but the least reported factor. Considering that it has really very fewer dimensions attached to it. The few sub measures found were luxuriousness, simplicity, attractiveness

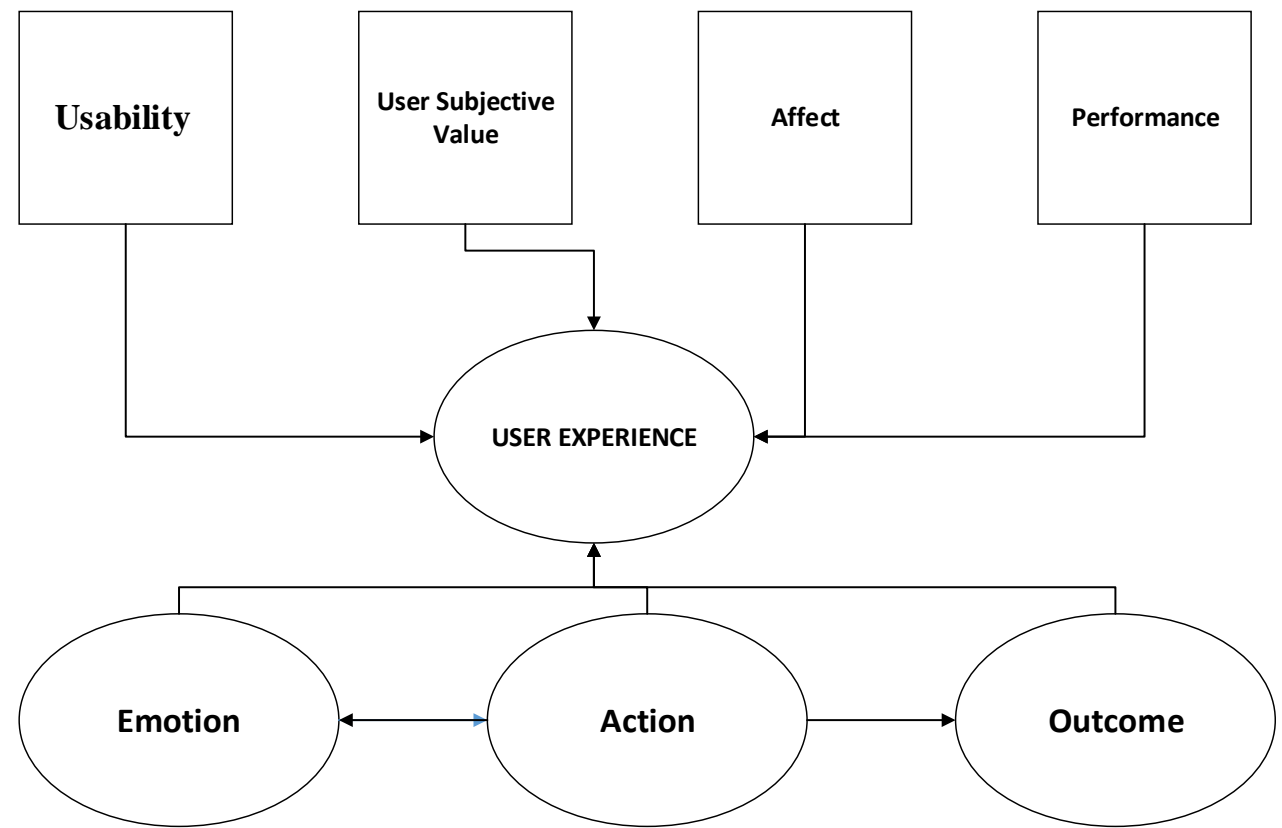

\section{CONCLUSION}

User Experience is a domain which needs its definition. Still there is a vast scope of study in this domain. UX can only be conceptualized rather than defined.

The features found in this paper doesnot still represent the complete picture. There is still a need of more features to be added and tested. Also the measurement of UX is still not reported widely and needs elaboration.

Future researchers may take a look on using factors in this research and test it for a larger sample so that UX can be predicted using regression analysis. Also PCA can be used to find the exact grouping of the subelements as elements.

\section{REFERENCES}

[1] Park, J., Han, S.H., Kim, H.K., Cho, Y. and Park, W., 2013. Developing elements of user experience for mobile phones and services: survey, interview, and observation approaches. Human Factors and Ergonomics in Manufacturing \& Service Industries, 23(4), pp.279-293.

[2] Korhonen, H., Arrasvuori, J. and Väänänen-Vainio-Mattila, K., 2010, December. Analysing user experience of personal mobile products through contextual factors. In Proceedings of the 9th International Conference on Mobile and Ubiquitous Multimedia (p. 11). ACM.

[3] Boztepe, S., 2007. User value: Competing theories and models. International journal of design, 1(2).

[4] Kujala, S., Roto, V., Väänänen-Vainio-Mattila, K., Karapanos, E. and Sinnelä, A., 2011. UX Curve: A method for evaluating long-term user experience. Interacting with Computers, 23(5), pp.473-483.

[5] Hassenzahl, M., Diefenbach, S. and Göritz, A., 2010 Needs, affect, and interactive products-Facets of user experience. Interacting with computers,22(5), pp.353-362.

[6] Battarbee, K., 2003, June. Defining co-experience. In Proceedings of the 2003 international conference on Designing pleasurable products and interfaces (pp. 109113). ACM.

[7] Forlizzi, J. and Battarbee, K., 2004, August. Understanding experience in interactive systems. In Proceedings of the 5th conference on Designing interactive systems: processes, practices, methods, and techniques (pp. 261-268). ACM.

[8] Choi, H., Choi, Y.J. and Kim, K.M., 2012. The understanding of building trust model on smartphone 
application: focusing on users' motivation. InProceedings of the International Conference on IT Convergence and Security 2011 (pp. 13-20). Springer Netherlands.

[9] Harrison, R., Flood, D. and Duce, D., 2013. Usability of mobile applications: literature review and rationale for a new usability model. Journal of Interaction Science, 1(1), pp.1-16.

[10] Sun, Y., Chong, W.K., Han, Y.S., Rho, S. and Man, K.L., 2015. Key factors affecting user experience of mobile recommendation systems. InProceedings of the International MultiConference of Engineers and Computer Scientists (Vol. 2).

[11] Finstad, K., 2010. The usability metric for user experience. Interacting with Computers, 22(5), pp.323-327.

[12] Partala, T. and Kallinen, A., 2012. Understanding the most satisfying and unsatisfying user experiences: Emotions, psychological needs, and context.Interacting with computers, 24(1), pp.25-34. 